\title{
Automated gait event detection for a variety of locomotion tasks using a novel gyroscope-based algorithm
}

\author{
Cagla Fadillioglu ${ }^{\mathrm{a}, 1}$, Bernd J. Stetter ${ }^{\mathrm{a}, 1, *}$, Steffen Ringhof ${ }^{\mathrm{a}, \mathrm{b}}$, Frieder C. Krafft ${ }^{\mathrm{a}}$, Stefan Sell ${ }^{\mathrm{a}, \mathrm{c}}$, \\ Thorsten Stein ${ }^{\mathrm{a}}$ \\ ${ }^{a}$ Institute of Sports and Sports Science, Karlsruhe Institute of Technology, Engler-Bunte-Ring 15, 76131 Karlsruhe, Germany \\ ${ }^{\mathrm{b}}$ Department of Sport and Sport Science, University of Freiburg, Schwarzwaldstr. 175, 79117 Freiburg, Germany \\ c Joint Center Black Forest, Hospital Neuenbuerg, 75305 Neuenbuerg, Germany
}

\begin{abstract}
A B S T R A C T
Keywords:

Wearable sensors

Rule-based algorithm

Initial contact

Toe-off

Linear movements

Turning conditions

Background: The robust identification of initial contact (IC) and toe-off (TO) events is a vital task in mobile sensor-based gait analysis. Shank attached gyroscopes in combination with suitable algorithms for data processing can robustly and accurately complete this task for gait event detection. However, little research has considered gait detection algorithms that are applicable to different locomotion tasks.

Research question: Does a gait event detection algorithm for various locomotion tasks provide comparable estimation accuracies as existing task-specific algorithms?

Methods: Thirteen males, equipped with a gyroscope attached to the right shank, volunteered to perform nine different locomotion tasks consisting of linear movements and movements with a change of direction. A rulebased algorithm for IC and TO events was developed based on the shank sagittal plane angular velocity. The algorithm was evaluated against events determined by vertical ground reaction force. Absolute mean error (AME), relative absolute mean error (RAME) and Bland-Altman analysis was used to assess its accuracy.

Results: The average AME and RAME were $11 \pm 3 \mathrm{~ms}$ and $3.07 \pm 1.33 \%$, respectively, for IC and $29 \pm 11 \mathrm{~ms}$ and $7.27 \pm 2.92 \%$, respectively, for TO. Alterations of the walking movement, such as turns and types of running, slightly reduced the accuracy of IC and TO detection. In comparison to previous methods, increased or comparable accuracies for both IC and TO detection are shown.

Significance: The study shows that the proposed algorithm is capable of detecting gait events for a variety of locomotion tasks by means of a single gyroscope located on the shank. In consequence, the algorithm can be applied to activities, which consist of various movements (e.g., soccer). Ultimately, this extends the use of mobile sensor-based gait analysis.
\end{abstract}

\section{Introduction}

Gait analysis has a broad scope of applications including sports, rehabilitation and medicine [1 3]. Independent of the area of appli cation, the detection of two fundamental gait events, namely initial contact (IC) and toe off (TO), is essential. The identification of these events is mandatory for subsequent identification of gait features that are related to movement quality, such as stance phase, swing phase, step and stride [4].

Gait event detection can be performed by means of different systems and sensors with various capabilities [5]. A fully equipped bio mechanics laboratory usually includes force plates as the gold standard system for IC and TO detection [6]. However, laboratory measurements have some disadvantages, including requiring substantial human, time and financial resources, having experimental setups restricted to those possible in laboratory conditions [1]. Furthermore, clinical settings can lead to altered movement patterns [7]. Mobile sensors may be helpful to overcome these disadvantages by eliminating cost and portability limitations set by laboratory settings [8]. Various algorithms applicable to mobile sensors have been developed over the last two decades in order to detect gait events in more ecological gait settings [9].

Most gait analysis studies with mobile sensors have focused on walking, which is the primary form of locomotion and thus plays a crucial role in human life [10]. Gouwanda and Gopalai [11]

\footnotetext{
* Corresponding author.

E-mail address: bernd.stetter@kit.edu (B.J. Stetter).

${ }^{1}$ These authors contributed equally to this work.
} 
implemented an algorithm, based on a single gyroscope on the shank, for gait event detection during walking in different conditions (normal walking; walking with knee brace; and walking with ankle brace for overground and treadmill walking). They suggested that gyroscopes are the most suitable devices for gait monitoring systems. Storm et al. [12] evaluated the accuracy of two algorithms one based on two shank worn inertial sensors, and the other based on a single waist worn sensor for the detection of gait events and temporal parameters during walking. The results highlighted that the shank based method showed very accurate estimations ( $\leq 14 \mathrm{~ms}$, mean error), outperforming the waist worn method. Furthermore, a limited number of studies have investigated event detection during running [[12],13 16]. Satisfactory results ( $\leq 25 \mathrm{~ms}$, Bland Altman $95 \%$ limits of agreement; LoA) for stance time have been obtained using accelerometer based algorithms and a mobile sensor located at the lower back [[12],13], as well as from a combination of accelerometers and gyroscopes attached to the ankle [14]. Changes of direction including walking turns and running cuts have not yet received much attention [[14]]. An algorithm robust en ough to be used in different locomotion tasks without requiring activity classification would extend the use of mobile sensors.

Rule based and adaptive algorithms are most commonly applied for automated IC and TO detection. Rule based algorithms are mostly ap plied to a single type of movement task [[17]], while studies of more than one task undertake gait event detection with adaptive algorithms: e.g., dynamic time warping [17] and hidden Markov models [18]. However, adaptive algorithms models require input data for training, which costs time and extra work [5], whereas rule based algorithms are quicker and easier to implement. Furthermore, in terms of estimation accuracy, rule based algorithms are capable of providing accurate re sults ( $\leq 22 \mathrm{~ms}$, mean error) [19].

Therefore, the purpose of this study was to investigate whether a gait event detection algorithm for various locomotion tasks would provide comparable estimation accuracies as existing, task specific al gorithms. A novel rule based gait event detection algorithm was de veloped based on previously described algorithms using shank attached gyroscopes [11,12], and its accuracy was evaluated for a variety of locomotion tasks. This algorithm broadens the scope of applications to different locomotion tasks and has potential to be utilized in further studies as well as in the research and development of smart knee braces [3] or fitness monitors for investigation of everyday and sports activ ities.

\section{Materials and methods}

\subsection{Subjects}

A group of 13 males (age: $26.1 \pm 2.9$ years; height: $178.7 \pm 5.5 \mathrm{~cm}$; mass: $78.4 \pm 5.9 \mathrm{~kg}$ ) volunteered in this study. All participants were free from injury at the time of experiment. The study was approved by the ethics committee of the Karlsruhe Institute of Technology. All participants were informed of the experimental pro cedures and gave informed written consent prior to the experiment.

\subsection{Data collection}

A single axis gyroscope $\left(1500 \mathrm{~Hz}\right.$, ADXRS652, $\pm 250^{\circ} / \mathrm{s}$ Yaw Rate Gyro, Analog Devices Inc., Norwood, MA, USA) was attached to each participant's right leg via an elastic knee sleeve. This gyroscope was positioned in an outside pocket at the lower frontal end of the sleeve in order to capture the angular velocity of the shank in the sagittal plane $[12,20]$

After warm up jogging for five minutes on a treadmill with self selected speed, participants were instructed to complete nine different locomotion tasks in the following order: walking straight, moderate and fast running, $90^{\circ}$ walking turns to the left and right and $45^{\circ}$ and $90^{\circ}$ running cuts to the left and right [20]. All locomotion tasks, except for fast running, were performed with a self selected speed. Fast running was set at $150 \%$ of the moderate running speed, controlled by light barriers (TAG Heuer, La Chaux de Fonds, Switzerland).

All locomotion tasks were repeated until three valid trials were re corded. Two floor embedded AMTI $(1000 \mathrm{~Hz}, \mathrm{BP} 600900$, Advanced Mechanical Technology Inc., Watertown, MA, USA) force plates were used to measure 3D ground reaction forces (GRF) as a reference system for IC and TO detection.

\subsection{Data processing}

All data processing was done using MATLAB $^{\mathrm{TM}}$ R2018b (The MathWorks Inc., Natick, MA, USA). A $15 \mathrm{~Hz}$ 4th order Butterworth low pass filter was applied to the GRF and angular velocity signals [21]. Offset correction of the angular velocity signals was done by subtracting the mean value of a neutral standing sequence. Angular velocity and GRF data were time synchronized with each other using a synchroni zation pulse sent from the GRF measurement system to the angular velocity measurement system each time data acquisition was initiated. For the segmentation of GRF data, IC and TO were defined as the time instant when the GRF first rose above $10 \mathrm{~N}$ and reduced to $10 \mathrm{~N}$, re spectively [22].

\subsection{Algorithm description}

The general block scheme of the proposed algorithm is shown in Fig. 1. Sagittal angular velocity of the shank was utilized as the input, whereupon firstly the mid swing and then IC and TO were computed.

\subsubsection{Mid swing detection}

Mid swing was detected to define search windows in the signal for the identification of IC and TO events [11,12]. A positive peak detec tion was carried out by utilizing a proper threshold value of $1000 \mathrm{mV}$, which was chosen according to the data characteristics $[5,8]$. All of the positive peaks had to fulfill the condition for a plausible gait cycle duration, i.e. occurring at least 500 frames $(\cong 333 \mathrm{~ms}$ ) later than the preceding one $[5,8]$. All of the detected mid swing peaks were pro cessed stepwise to locate the corresponding IC and TO events.

\subsubsection{Initial contact detection}

Fig. 2 illustrates the process of IC detection, which was based on the identification of the negative going angular rate reversal point during each gait cycle in accordance with Hundza et al. [23]. This point has proven to be a highly accurate measurement of the termination of forward swing as the negative going rate reversal is close in timing to the heel contact [23]. This reversal was identified by the first zero crossing occurring after mid swing peak and was defined as IC.

\subsubsection{Toe off detection}

Fig. 3 illustrates the process of TO detection. A complementary signal was calculated by calculating the difference signal using the unfiltered signal and the previously described $15 \mathrm{~Hz}$ low pass filtered signal [24,25]. A $10 \mathrm{~Hz}$ low pass filter (2nd order Butterworth) was used to smooth the complementary signal. Additionally, the preceding negative peak of the mid swing peak in the filtered signal was identified to locate a search window for TO detection. Depending on the gait cycle duration, which was determined as the time between two mid swing peaks, two different search windows were defined for slow (gait cycle duration $>1 \mathrm{~s}$ ) and fast locomotion tasks (gait cycle duration $<1 \mathrm{~s}$ ) [26]. The search window for slow locomotion tasks started at $50 \%$ of the gait cycle duration and ended at the negative peak plus $10 \%$ of the gait cycle duration. For fast locomotion tasks, the search window started at $50 \%$ of the gait cycle duration and ended at the negative peak. TO for slow locomotion tasks was identified by detecting the minimum of the complementary signal in the search window. In con trast, it was identified as the maximum of the complementary signal in 


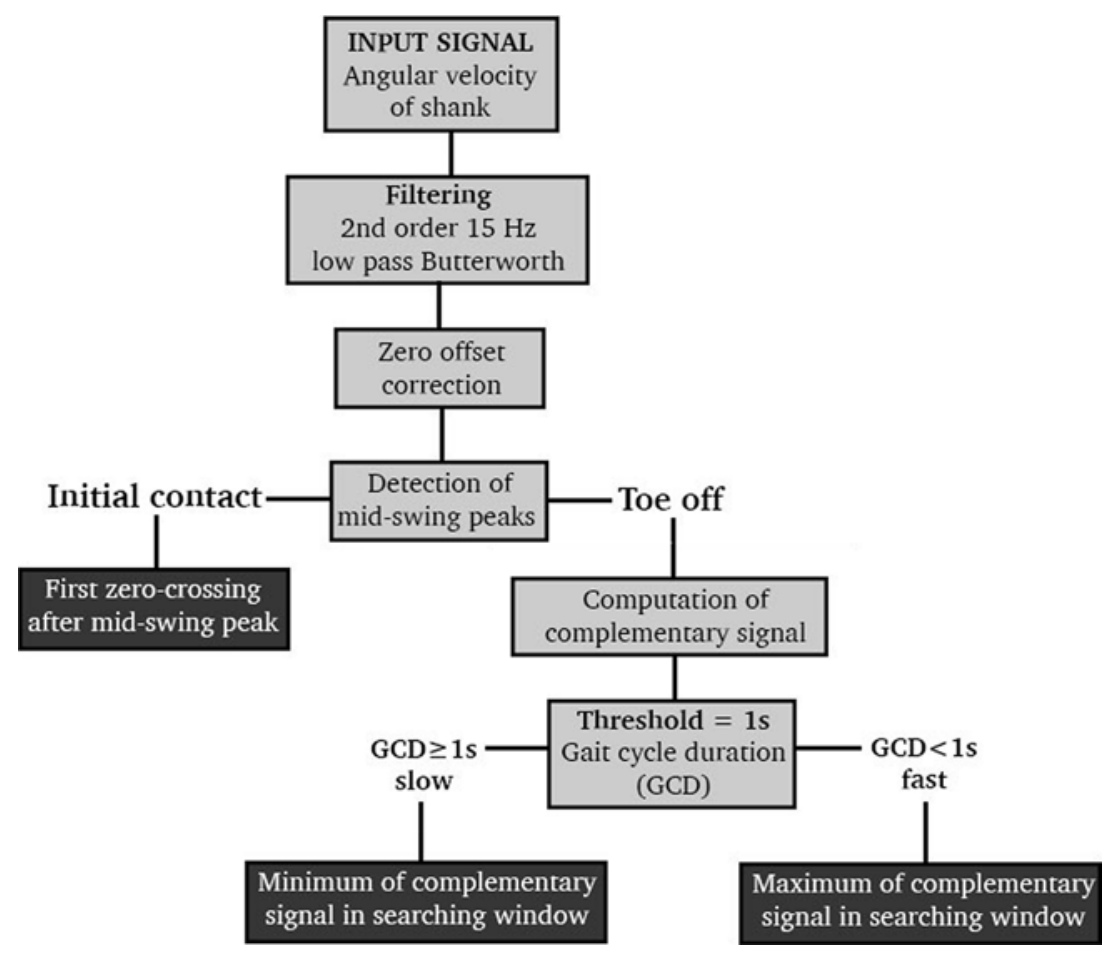

Fig. 1. Algorithm flowchart for detection of initial contact and toe-off events.

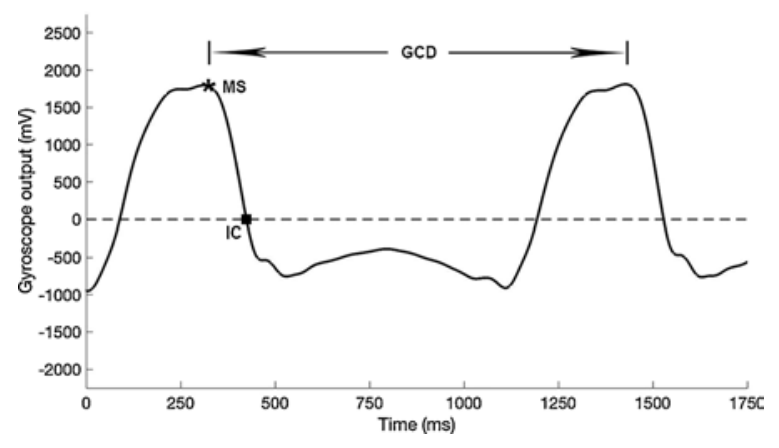

Fig. 2. Initial contact (IC) detection algorithm applied on a walking gait cycle (GCD: gait cycle duration). Solid and dashed lines represent the zero offset corrected signal and zero line, respectively. Mid-swing (MS) peak is indicated by the asterisk. IC was identified by the first zero crossing after MS (indicated by the square).

the search window for fast locomotion tasks.

\subsection{Error calculations and statistics}

Absolute mean errors (AMEs) of IC and TO were evaluated by cal culating the difference between the algorithm based and the GRF based events. Relative AME (RAME) was determined by normalizing the AME to the respective stance time obtained from the GRF data. This was done to obtain reasonably comparable results among different loco motion tasks.

Statistical tests were computed with IBM SPSS Statistics (Version 25.0, SPSS Inc., IBM, Armonk, NY, USA). Kolmogorov Smirnov and Shapiro Wilk tests assessed the normality of the distributions of AME and RAME data [27]. The tests indicated non normal distributions and therefore led to the computation of the non parametric Friedman test to check for differences in AME and RAME between locomotion tasks. When significant differences were found, Dunn's post hoc test was implemented and Bonferroni correction was used to adjust for multiple comparisons. The level of significance both for the Friedman test and (a)
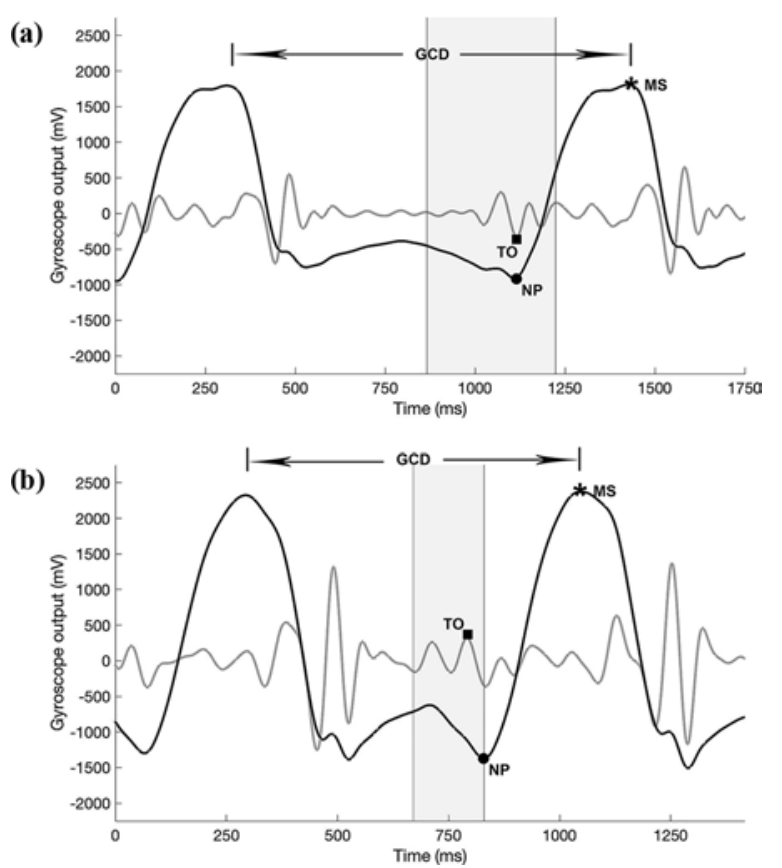

Fig. 3. Illustration of toe-off (TO) detection for (a) slow and (b) fast locomotion tasks. Black and gray solid lines represent the main and complementary signals, respectively. The negative peak (NP) used for the search window is depicted by the black circle, and the mid-swing peak (MS) in the process is depicted by the asterisk. (a) TO detection algorithm applied to a gait cycle (GCD: gait cycle duration) of a slow locomotion task (walking). The shaded area depicts the search window for TO starting at GCD/2 and ending at [NP + GCD x 0.1$]$ of the main signal. The minimum complementary signal in this window was identified as TO. (b) TO detection algorithm applied on a GCD of a fast locomotion task (moderate running). The shaded area depicts the search window for TO starting at GCD/2 and ending at NP of the main signal. The maximum complementary signal in this window was identified as TO. 
Table 1

Absolute mean error (AME) and relative absolute mean error (RAME) for initial contact (IC) and toe-off (TO) of all locomotion tasks. Values are presented as mean (standard deviation); $\mathrm{L}=$ left; $\mathrm{R}=$ right.

\begin{tabular}{llllll}
\hline Locomotion task & \multicolumn{2}{l}{ IC } & & TO \\
\cline { 2 - 3 } \cline { 5 - 6 } & $\begin{array}{l}\text { AME } \\
\text { in } \mathrm{ms}\end{array}$ & $\begin{array}{l}\text { RAME } \\
\text { in } \%\end{array}$ & & $\begin{array}{l}\text { AME } \\
\text { in ms }\end{array}$ & $\begin{array}{l}\text { RAME } \\
\text { in \% }\end{array}$ \\
\hline Walking & $7(3)$ & $1.04(0.48)$ & & $19(11)$ & $2.86(1.62)$ \\
Moderate running & $10(4)$ & $3.35(1.38)$ & & $26(20)$ & $8.00(4.80)$ \\
Fast running & $13(6)$ & $5.50(2.70)$ & & $23(23)$ & $9.43(8.76)$ \\
$90^{\circ}$ walking turn $\mathrm{L}$ & $16(15)$ & $2.46(2.58)$ & & $38(25)$ & $5.71(4.05)$ \\
$90^{\circ}$ walking turn $\mathrm{R}$ & $10(5)$ & $1.48(0.81)$ & & $34(18)$ & $4.81(2.43)$ \\
$90^{\circ}$ running cut $\mathrm{L}$ & $11(7)$ & $2.97(1.90)$ & & $34(26)$ & $9.15(6.80)$ \\
$90^{\circ}$ running cut $\mathrm{R}$ & $12(6)$ & $3.21(1.63)$ & & $49(25)$ & $12.47(6.30)$ \\
$45^{\circ}$ running cut $\mathrm{L}$ & $9(5)$ & $3.50(2.04)$ & & $14(5)$ & $5.23(1.72)$ \\
$45^{\circ}$ running cut $\mathrm{R}$ & $11(5)$ & $4.09(1.85)$ & & $21(15)$ & $7.74(5.03)$ \\
Average & $11(3)$ & $3.07(1.33)$ & & $29(11)$ & $7.27(2.92)$ \\
\hline
\end{tabular}

for the post hoc test was a priori set at $\mathrm{p} \leq 0.05$. Effect sizes were provided by calculating Kendall's concordance coefficient (W) [28] and Cohen's d [29], and interpreted according to Cohen's Guideline $[29,30]$. Hence for $\mathrm{W}$ and for Cohen's d effect sizes of $0.10-0.30$, $0.30-0.50$ and $>0.50$ indicate small, medium and large effects, re spectively. Validation of stance time was performed by creating Blan d Altman plots [31]. Latency of IC and TO detections were represented by mean errors (ME) on these plots. A positive ME was associated with a late detection, and vice versa.

\section{Results}

The time differences (AME and RAME) between gait events esti mated by the proposed algorithm and obtained by the reference system for all locomotion tasks are illustrated in Table 1. The effect sizes and the significant differences for pairwise comparisons of all locomotion tasks are presented in Table 2.

\subsection{Initial contact detection}

The average AME for IC among all locomotion tasks was $11 \pm 3 \mathrm{~ms} .90^{\circ}$ walking turns to the left yielded the highest AME for IC (mean \pm standard deviation: $16 \pm 15 \mathrm{~ms}$ ), whereas walking straight had the lowest time differences among all locomotion tasks $(7 \pm 3 \mathrm{~ms})$. Friedman test did not show any significant differences for AME in terms of IC.

The average RAME for IC was $3.07 \pm 1.33 \%$. The RAMEs were highest for fast running $(5.50 \pm 2.70 \%)$ and lowest for straight walking $(1.04 \pm 0.48 \%)$. Friedman test showed significant differences with a moderate effect size ( $\mathrm{p} \leq 0.001, \mathrm{~W}=0.42$ ) for RAME in terms of IC. Dunn's post hoc test revealed that the RAME for IC during straight walking was significantly lower with strong effect sizes compared to those of moderate $(\mathrm{p}=0.003, \mathrm{~d}=2.24)$ and fast $(\mathrm{p} \leq 0.001, \mathrm{~d}=2.30)$ running, $90^{\circ}$ running cuts to the right $(\mathrm{p}=0.027, \mathrm{~d}=1.80)$ and $45^{\circ}$ running cuts to the left $(\mathrm{p}=0.021, \mathrm{~d}=1.67)$ and right $(\mathrm{p} \leq 0.001$, $\mathrm{d}=2.26$ ). $90^{\circ}$ walking turns to the right had significantly lower RAME with strong effect sizes for IC than fast running $(p=0.001, d=-2.02)$ and $45^{\circ}$ running cuts to the right ( $\mathrm{p}=0.027, \mathrm{~d}=1.83$ ).

\subsection{Toe off detection}

The average AME for TO among all locomotion tasks was $29 \pm 11 \mathrm{~ms} .90^{\circ}$ running cuts to the right yielded the highest AME for TO (49 $\pm 25 \mathrm{~ms}$ ), whereas $45^{\circ}$ running cut to the left had the lowest time differences $(14 \pm 5 \mathrm{~ms})$. Friedman test yielded significant differ ences with a moderate effect size for $\operatorname{AME}(p \leq 0.001, W=0.32)$ in terms of TO. According to the post hoc test, the AME for TO during $45^{\circ}$ running cuts to the left was significantly lower with strong effect sizes compared to those of $90^{\circ}$ walking turns to the left $(\mathrm{p}=0.007, \mathrm{~d}=$ $-1.33)$ and to the right $(\mathrm{p}=0.036, \mathrm{~d}=-1.56)$ as well as $90^{\circ}$ running cuts to the left $(\mathrm{p}=0.021, \mathrm{~d}=-1.12)$ and right $(\mathrm{p} \leq 0.001, \mathrm{~d}=$ -1.98). Additionally, the AME for TO was significantly lower with a strong effect size for straight walking than for $90^{\circ}$ running cuts to the right $(\mathrm{p}=0.046, \mathrm{~d}=1.56)$.

In terms of TO, Friedman test yielded significant differences with a moderate effect size also for RAME ( $\leq 50.001, \mathrm{~W}=0.33$ ). Post hoc test suggested that the average RAME for TO was $7.27 \pm 2.92 \%$; the highest was for $90^{\circ}$ running cuts to the right (12.47 $\left.\pm 6.30 \%\right)$, and the lowest was for straight walking $(2.86 \pm 1.62 \%)$, which was sig nificantly lower with strong effect sizes compared to those for moderate $(\mathrm{p}=0.007, \mathrm{~d}=1.43)$ and fast running $(\mathrm{p}=0.036, \mathrm{~d}=1.04), 90^{\circ}$ running cuts to the left $(\mathrm{p}=0.003, \mathrm{~d}=1.27)$ and right $(\mathrm{p} \leq 0.001$, $\mathrm{d}=2.09)$ and $45^{\circ}$ running cuts to the right $(\mathrm{p}=0.027, \mathrm{~d}=1.30)$.

\subsection{Bland Altman analysis}

The Bland Altman plots in Fig. 4 show that limits of agreement were smaller than $150 \mathrm{~ms}$ for all locomotion tasks. $90^{\circ}$ running cuts to

\section{Table 2}

Effect sizes (Cohen's d) for pairwise comparisons of all locomotion tasks for absolute mean error (AME) and relative absolute mean error (RAME) of the detected gait events. Upper and lower triangular matrices represent initial contact (IC) and toe-off (TO) results, respectively. In each cell, corresponding effects sizes for AME and RAME are shown one below the other. Pairwise comparisons with significant differences ( $\mathrm{p} \leq 0.05$ after Bonferroni correction) according to the Dunn's post-hoc test are highlighted in bold type; $\mathrm{L}=$ left; $\mathrm{R}=$ right.

\begin{tabular}{|c|c|c|c|c|c|c|c|c|c|c|}
\hline $\begin{array}{l}\text { AME } \\
\text { RAME }\end{array}$ & \multicolumn{10}{|l|}{ IC } \\
\hline \multirow{10}{*}{ TO } & $\begin{array}{l}\text { Locomotion } \\
\text { task }\end{array}$ & Walking & $\begin{array}{l}\text { Moderate } \\
\text { running }\end{array}$ & $\begin{array}{l}\text { Fast } \\
\text { running }\end{array}$ & $\begin{array}{l}90^{\circ} \\
\text { walking } \\
\text { turn L }\end{array}$ & $\begin{array}{l}90^{\circ} \\
\text { walking } \\
\text { turn } \mathrm{R}\end{array}$ & $\begin{array}{l}90^{\circ} \\
\text { running } \\
\text { turn L }\end{array}$ & $\begin{array}{l}90^{\circ} \\
\text { running } \\
\text { turn } \mathrm{R}\end{array}$ & $\begin{array}{l}45^{\circ} \\
\text { running } \\
\text { cut L }\end{array}$ & $\begin{array}{l}45^{\circ} \\
\text { running } \\
\text { cut } R\end{array}$ \\
\hline & Walking & & $\begin{array}{l}0.82 \\
2.24\end{array}$ & $\begin{array}{l}1.09 \\
\mathbf{2 . 3 0}\end{array}$ & $\begin{array}{l}0.82 \\
0.77\end{array}$ & $\begin{array}{l}0.70 \\
0.67\end{array}$ & $\begin{array}{l}0.67 \\
1.39\end{array}$ & $\begin{array}{l}1.11 \\
1.80\end{array}$ & $\begin{array}{l}0.40 \\
1.67\end{array}$ & $\begin{array}{l}0.80 \\
2.26\end{array}$ \\
\hline & $\begin{array}{l}\text { Moderate } \\
\text { running }\end{array}$ & $\begin{array}{l}0.43 \\
1.43\end{array}$ & & $\begin{array}{l}0.49 \\
1.00\end{array}$ & $\begin{array}{l}0.56 \\
-0.43\end{array}$ & $\begin{array}{l}0.06 \\
-1.66\end{array}$ & $\begin{array}{l}0.15 \\
-0.23\end{array}$ & $\begin{array}{l}0.49 \\
-0.10\end{array}$ & $\begin{array}{l}-0.28 \\
0.09\end{array}$ & $\begin{array}{l}0.11 \\
0.45\end{array}$ \\
\hline & $\begin{array}{l}\text { Fast } \\
\text { running }\end{array}$ & $\begin{array}{l}0.17 \\
\mathbf{1 . 0 4}\end{array}$ & $\begin{array}{l}-0.18 \\
0.20\end{array}$ & & $\begin{array}{l}0.33 \\
-1.15\end{array}$ & $\begin{array}{l}-0.37 \\
-2.02\end{array}$ & $\begin{array}{l}-0.24 \\
-10.8\end{array}$ & $\begin{array}{l}-0.01 \\
-1.03 \\
\end{array}$ & $\begin{array}{l}-0.66 \\
-0.84\end{array}$ & $\begin{array}{l}-0.36 \\
-0.61\end{array}$ \\
\hline & $\begin{array}{l}90^{\circ} \text { walking } \\
\text { turn L }\end{array}$ & $\begin{array}{l}0.96 \\
0.92\end{array}$ & $\begin{array}{l}0.51 \\
-0.52\end{array}$ & $\begin{array}{l}0.65 \\
-0.55\end{array}$ & & $\begin{array}{l}-0.52 \\
-0.52\end{array}$ & $\begin{array}{l}-0.45 \\
0.22\end{array}$ & $\begin{array}{l}-0.33 \\
0.34\end{array}$ & $\begin{array}{l}-0.65 \\
0.45\end{array}$ & $\begin{array}{l}-0.51 \\
0.73\end{array}$ \\
\hline & $\begin{array}{l}90^{\circ} \text { walking } \\
\text { turn } \mathrm{R}\end{array}$ & $\begin{array}{l}1.00 \\
0.94\end{array}$ & $\begin{array}{l}0.41 \\
-0.84\end{array}$ & $\begin{array}{l}0.57 \\
-0.72\end{array}$ & $\begin{array}{l}-0.18 \\
-0.27\end{array}$ & & $\begin{array}{l}0.09 \\
1.02\end{array}$ & $\begin{array}{l}0.38 \\
1.34\end{array}$ & $\begin{array}{l}-0.28 \\
1.30\end{array}$ & $\begin{array}{l}0.04 \\
1.83\end{array}$ \\
\hline & $\begin{array}{l}90^{\circ} \text { running } \\
\text { turn L }\end{array}$ & $\begin{array}{l}0.76 \\
1.27\end{array}$ & $\begin{array}{l}0.35 \\
0.19\end{array}$ & $\begin{array}{l}0.49 \\
-0.04\end{array}$ & $\begin{array}{l}-0.15 \\
0.61\end{array}$ & $\begin{array}{l}0.01 \\
0.85\end{array}$ & & $\begin{array}{l}0.24 \\
0.13\end{array}$ & $\begin{array}{l}-0.34 \\
0.27\end{array}$ & $\begin{array}{l}-0.06 \\
0.60\end{array}$ \\
\hline & $\begin{array}{l}90^{\circ} \text { running } \\
\text { turn } \mathrm{R}\end{array}$ & $\begin{array}{l}1.56 \\
2.09\end{array}$ & $\begin{array}{l}1.00 \\
0.80\end{array}$ & $\begin{array}{l}1.12 \\
0.40\end{array}$ & $\begin{array}{l}0.43 \\
1.28\end{array}$ & $\begin{array}{l}0.69 \\
1.61\end{array}$ & $\begin{array}{l}0.58 \\
0.51\end{array}$ & & $\begin{array}{l}-0.67 \\
0.16\end{array}$ & $\begin{array}{l}-0.36 \\
0.51\end{array}$ \\
\hline & $\begin{array}{l}45^{\circ} \text { running } \\
\text { cut } \mathrm{L}\end{array}$ & $\begin{array}{l}-0.6 \\
1.419\end{array}$ & $\begin{array}{l}-0.85 \\
-0.77\end{array}$ & $\begin{array}{l}-0.53 \\
-0.67\end{array}$ & $\begin{array}{l}-1.33 \\
-0.15\end{array}$ & $\begin{array}{l}-1.56 \\
0.20\end{array}$ & $\begin{array}{l}-1.12 \\
-0.79\end{array}$ & $\begin{array}{l}-\mathbf{- 1 . 9 8} \\
-1.57\end{array}$ & & $\begin{array}{l}0.34 \\
0.30\end{array}$ \\
\hline & $\begin{array}{l}45^{\circ} \text { running } \\
\text { cut } R\end{array}$ & $\begin{array}{l}0.09 \\
1.30\end{array}$ & $\begin{array}{l}-0.32 \\
-0.05\end{array}$ & $\begin{array}{l}-0.10 \\
-0.24\end{array}$ & $\begin{array}{l}-0.85 \\
0.45\end{array}$ & $\begin{array}{l}-0.83 \\
0.74\end{array}$ & $\begin{array}{l}-0.66 \\
-0.23\end{array}$ & $\begin{array}{l}-1.40 \\
-0.83\end{array}$ & $\begin{array}{l}0.62 \\
0.67\end{array}$ & \\
\hline
\end{tabular}



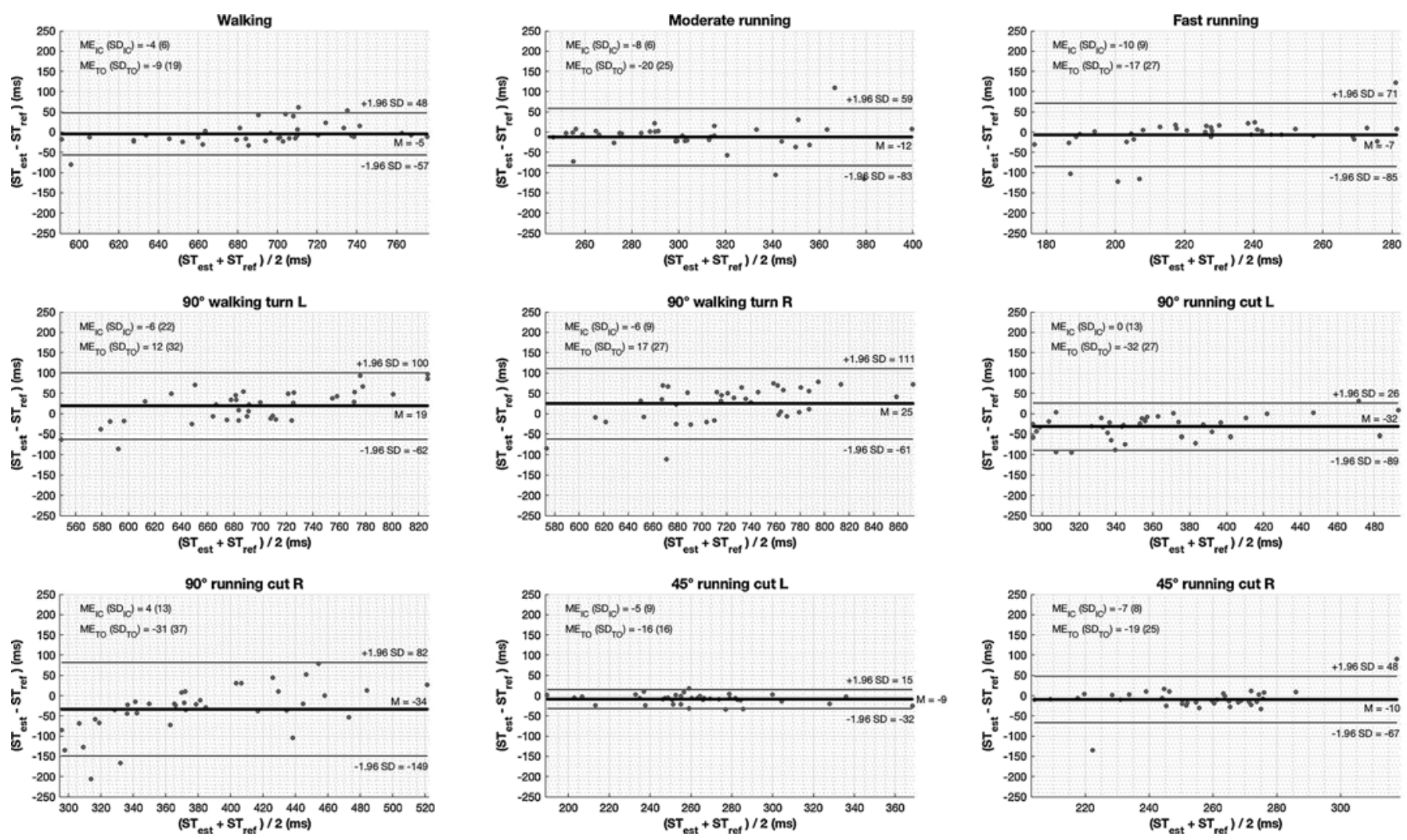

Fig. 4. Bland-Altman plots for stance time (ST) with mean differences (thick lines) and limits of agreement (95\% LoA) (thin lines) represented for all locomotion tasks (a to $\mathrm{i}$; where $\mathrm{L}=$ left, $\mathrm{R}=$ right). Actual values of mean differences and $95 \% \mathrm{LoA}$ are shown in the right end of the respective lines. Mean error (ME) and standard deviation (SD) of initial contact (IC) and toe-off (TO) are illustrated in the left top corner of each subplot. Values are presented in milliseconds (ms).

the right exhibited the largest limit of agreement (lower limit, $-149 \mathrm{~ms}$ ) as well as the highest bias (mean line at $-34 \mathrm{~ms}$ ), which reflects an underestimation of the stance time. All other locomotion tasks, except for the two walking turn tasks, also showed under estimations of the stance time with biases smaller than $32 \mathrm{~ms} .90^{\circ}$ walking turns to the left and right demonstrated positive mean lines (19 and $25 \mathrm{~ms}$, respectively), indicating overestimations of the stance time.

A slightly early and late detection of IC is indicated by the MEs, which ranged between 8 and $4 \mathrm{~ms}$ for individual tasks. For TO detec tion, the mean latency range was larger than that of IC ( 32 and $17 \mathrm{~ms}$ ).

\section{Discussion}

\subsection{Summary of results}

This study developed and validated a novel rule based gait event detection algorithm based on a shank attached gyroscope across var ious locomotion tasks. IC and TO events were compared to laboratory assessed vertical GRFs. Including turning and cutting maneuvers is es sential in order to broaden the scope of automated gait event detection algorithms. The results indicate that the accuracy varied between lo comotion tasks. The highest accuracy for IC detection was seen for straight walking (lowest AME and RAME), which also showed the smallest RAME for TO detection. More elaborate walking movements as well as various types of running resulted in slightly reduced accuracy for IC and TO detection. With respect to the two different gait events, smaller average AME and RAME were seen for IC detection than for TO detection.

\subsection{Characteristics of the proposed algorithm}

The proposed algorithm was developed by modifying existing algorithms [11,12,23,32,33].

Unlike other studies that identified IC as the instant of minimum angular velocity [11,12], in this study first zero crossing after mid swing peak in angular velocity was preferred. Because before IC, there is an angular deceleration of the shank in preparation for foot place ment (i.e., the angular velocity of the shank decreases, and reaches zero at the instance of IC). Once the foot has contact with the ground, there exists an angular acceleration of the shank in the opposite direction (i.e., the absolute angular velocity of shank starts to increase, while the value continues to decrease as its sign has changed) [34].

A TO detection algorithm was developed, inspired by the studies of Mannini et al. [32] and Sabatini [25], which both computed a differ ence signal between filtered and unfiltered signals use in TO detection. They utilized a computed complementary signal for identifying the proper window for TO search. However, in this study, this signal was used directly for TO detection. Considering the difference signal be tween an unfiltered and low pass filtered signal enables the detection of frequency changes over the gait cycle. Jasiewicz et al. [35] reported the existence of higher frequency components during the early and late stance phases, which were utilized as a feature for TO detection in this study.

Highest accuracy of the proposed algorithm was shown for straight walking. A possible reason for this is the repeatable characteristic with less variation of this locomotion task in comparison to the other loco motion tasks [36]. For some locomotion tasks, the results did not show any differences in AME between locomotion tasks but they did for RAME, and vice versa (Table 2). This can be explained by the different stance times of the locomotion tasks. For a given AME a longer stance time leads to a smaller RAME. Consequently, a slow locomotion task has a smaller RAME than a fast one, despite having similar AME, and vice versa. 
Table 3

Comparison of initial contact (IC) and toe-off (TO) detection accuracy with values reported in the literature. Values are in the format mean (standard deviation); $\mathrm{AME}=$ absolute mean error; $\mathrm{ME}=$ mean error.

\begin{tabular}{|c|c|c|c|c|c|}
\hline Study & Method & Locomotion task & Error parameter & $\begin{array}{l}\text { IC error } \\
\text { in } \mathrm{ms}\end{array}$ & $\begin{array}{l}\text { TO error } \\
\text { in } \mathrm{ms}\end{array}$ \\
\hline Novel method & a rule-based algorithm & Walking straight & AME & $7(3)$ & $19(11)$ \\
\hline \multirow[t]{2}{*}{ Catalfamo et al. [4] } & \multirow[t]{2}{*}{ a rule-based algorithm } & \multirow[t]{2}{*}{ Walking; multiple conditions } & AME & $15(6)-24(12)$ & $43(10)-73(12)$ \\
\hline & & & ME & $21(15)-8(9)$ & $43(10)-73(12)$ \\
\hline \multirow[t]{2}{*}{ Trojeniello et al. [19] } & \multirow[t]{2}{*}{ a rule-based algorithm } & \multirow[t]{2}{*}{ Walking; different groups of subjects } & AME & $10-22$ & $16-22$ \\
\hline & & & ME & $0(17)-22(9)$ & $0(15)-16(9)$ \\
\hline \multirow[t]{2}{*}{ Mannini et al. [32] } & \multirow[t]{2}{*}{ an adaptive algortihm } & \multirow[t]{2}{*}{ Walking; different groups of subjects } & AME & 33 & 25 \\
\hline & & & ME & $20(58)$ & $16(38)$ \\
\hline Storm et al. [12] & two rule based algorithms & Walking; multiple settings & ME & $11(9)-53(22)$ & $37(16)-79(19)$ \\
\hline Greene et al. [33] & an adaptive algorithm & Walking; different speeds & ME & $8(8)-1(4)$ & $33(14)-52(26)$ \\
\hline Jasiewicz et al. [35] & three rule-based algorithms & Walking; different groups of subjects & ME & $53(11)-15(17)$ & $22(25)-61(10)$ \\
\hline Novel method & a rule-based algorithm & Running; (moderate and fast) & AME & $10(4)-13(6)$ & $23(23)-26(20)$ \\
\hline Benson et al. [15] & two rule-based algorithms & Running; multiple conditions & ME & $16-53$ & $24-32$ \\
\hline Leitch et el. [16] & four rule-based algorithms & Running; multiple conditions & ME & $50(13)-100(64)$ & $28(10)-105(20)$ \\
\hline
\end{tabular}

\subsection{Comparison of studies}

After a thorough analysis of the literature, no threshold for a plausible error could be detected for any of the studied locomotion tasks. A probable explanation for this is that an acceptable range of error depends on research question and area of application, because of that it's difficult to set it at a certain level. Table 3 compares the actual findings with values reported in the literature that suggested accurate and satisfactory results. Previous rule based algorithms for walking revealed a slightly higher AME ( $>10 \mathrm{~ms}$ ) for IC and similar (Trojeniello et al. [19] > 16 ms) to higher (Catalfamo et al. [4] > $43 \mathrm{~ms}$ ) AME for TO (AME IC $=7 \pm 3 \mathrm{~ms}$, AME TO $=19 \pm 11 \mathrm{~ms}$ ). Comparable dif ferences were shown between algorithm based IC and TO estimations and GRF based reference values by means of adaptive algorithms $[32,33]$. When comparing the estimation accuracy for running, pre vious studies presented higher error ranges for IC and TO detection $[15,16]$.

\subsection{Limitations}

Although care was paid when fixing the gyroscope and the knee sleeve, the fixation technique cannot completely exclude any oscilla tions or misalignment of the gyroscope. Although it was reported that angular velocity of the shank in the sagittal plane is valid for gait event detection during walking in a very robust and accurate manner $[11,12]$, it is still unclear if it would be advantageous to combine other signal components of the gyroscope (frontal and transversal directions), especially for non linear movements. The sample group was homo geneous in age, sex, height and weight. Therefore, the proposed method cannot be generalized for all groups. It would be advisable to conduct further studies with other groups of subjects. Although the scope of applicability has been considerably extended by involving a variety of locomotion tasks in this study, there are still tasks that have not been incorporated (e.g., stair walking).

\section{Conclusion}

In conclusion, the proposed algorithm is capable of detecting gait events for a variety of locomotion tasks by means of a single gyroscope located on the shank. This algorithm has potential applicability in fu ture studies as well as in the research and development of wearable devices or fitness monitors.

\section{Declaration of Competing Interest}

The authors have no conflicts of interest to disclose.

\section{Acknowledgment}

Funding was provided by the German Federal Ministry for Economic Affairs and Energy under Grant No. 4136601TS5.

\section{References}

[1] S. Chen, J. Lach, B. Lo, G.Z. Yang, Toward pervasive gait analysis with wearable sensors: a systematic review, IEEE J. Biomed. Heal. Informatics 20 (2016) 1521-1537.

[2] E. Bergamini, P. Picerno, H. Pillet, F. Natta, P. Thoreux, V. Camomilla, Estimation of temporal parameters during sprint running using a trunk-mounted inertial measurement unit, J. Biomech. 45 (2012) 1123-1126.

[3] K. Rudolph, J. Sun, D.S. Reisman, K. Hauck, W. Joseph, Development of a smart knee brace, Spinal Cord 30 (2006) 201-208.

[4] P. Catalfamo, S. Ghoussayni, D. Ewins, Gait event detection on level ground and incline walking using a rate gyroscope, Sensors 10 (2010) 5683-5702.

[5] N.H. Ghassemi, J. Hannink, C.F. Martindale, H. Gaßner, M. Müller, J. Klucken, B.M. Eskofier, Segmentation of gait sequences in sensor-based movement analysis: a comparison of methods in Parkinson's disease, Sensors (Switzerland) 18 (2018) $1-15$.

[6] G.P. Panebianco, M.C. Bisi, R. Stagni, S. Fantozzi, Analysis of the performance of 17 algorithms from a systematic review: influence of sensor position, analysed variable and computational approach in gait timing estimation from IMU measurements, Gait Posture 66 (2018) 76-82.

[7] I. Hillel, E. Gazit, A. Nieuwboer, L. Avanzino, L. Rochester, A. Cereatti, U. Della Croce, M.O. Rikkert, B.R. Bloem, E. Pelosin, S. Del Din, P. Ginis, N. Giladi, A. Mirelman, J.M. Hausdorff, Is every-day walking in older adults more analogous to dual-task walking or to usual walking? Elucidating the gaps between gait performance in the lab and during 24/7 monitoring, Eur. Rev. Aging Phys. Act. 16 (2019) 1-12.

[8] S. Díaz, J.B. Stephenson, M.A. Labrador, Use of wearable sensor technology in gait, balance, and range of motion analysis, Appl. Sci. 10 (2020).

[9] R. LeMoyne, T. Mastroianni, Portable Wearable and Wireless Systems for Gait and Reflex Response Quantification, (2018).

[10] J. Rueterbories, E.G. Spaich, O.K. Andersen, Gait event detection for use in FES rehabilitation by radial and tangential foot accelerations, Med. Eng. Phys. 36 (2014) 502-508.

[11] D. Gouwanda, A.A. Gopalai, A robust real-time gait event detection using wireless gyroscope and its application on normal and altered gaits, Med. Eng. Phys. 37 (2015) 219-225.

[12] F.A. Storm, C.J. Buckley, C. Mazzà, Gait event detection in laboratory and real life settings: accuracy of ankle and waist sensor based methods, Gait Posture 50 (2016) 42-46.

[13] J.B. Lee, R.B. Mellifont, B.J. Burkett, The use of a single inertial sensor to identify stride, step, and stance durations of running gait, J. Sci. Med. Sport 13 (2010) 270-273.

[14] M. Schmidt, C. Rheinländer, K.F. Nolte, S. Wille, N. Wehn, T. Jaitner, IMU-based determination of stance duration during sprinting, Procedia Eng. 147 (2016) 747-752.

[15] L.C. Benson, C.A. Clermont, R. Watari, T. Exley, R. Ferber, Automated 
accelerometer-based gait event detection during multiple running conditions, Sensors (Switzerland) 19 (2019) 1-19.

[16] J. Leitch, J. Stebbins, G. Paolini, A.B. Zavatsky, Identifying gait events without force plate during running: a comparison of methods, Gait Posture 33 (2011) 130-132.

[17] M. Derawi, P. Bours, Gait and activity recognition using commercial phones, Comput. Secur. 39 (PART B) (2013) 137-144.

[18] A. Mannini, A.M. Sabatini, Gait phase detection and discrimination between walking-jogging activities using hidden Markov models applied to foot motion data from a gyroscope, Gait Posture 36 (2012) 657-661.

[19] D. Trojaniello, A. Cereatti, E. Pelosin, L. Avanzino, A. Mirelman, J.M. Hausdorff, U. Della Croce, Estimation of step-by-step spazio-temporal parameters of normal and impaired gait using shank-mounted magneto-inertial sensors, J. Neuroeng. Rehabil. 11 (2014) 1-12.

[20] B.J. Stetter, S. Ringhof, F.C. Krafft, S. Sell, T. Stein, Estimation of knee joint forces in sport movements using wearable sensors and machine learning, Sensors 19 (2019) 3690 .

[21] J. Mickelborough, M.L. Van Der Linden, J. Richards, A.R. Ennos, Validity and reliability of a kinematic protocol for determining foot contact events, Gait Posture 11 (2000) 32-37.

[22] N. Eckardt, A. Kibele, Automatic identification of gait events during walking on uneven surfaces, Gait Posture 52 (2017) 83-86.

23] S.R. Hundza, W.R. Hook, C.R. Harris, S.V. Mahajan, P.A. Leslie, C.A. Spani, L.G. Spalteholz, B.J. Birch, D.T. Commandeur, N.J. Livingston, Accurate and reliable gait cycle detection in Parkinson's disease, IEEE Trans. Neural Syst. Rehabil. Eng. 22 (2014) 127-137.

[24] A. Mannini, A.M. Sabatini, A hidden Markov model-based technique for gait segmentation using a foot-mounted gyroscope, Proc. Annu. Int. Conf. IEEE Eng. Med. Biol. Soc. EMBS (2011) 4369-4373.

[25] A.M. Sabatini, Wearable sensor systems in biomechanics: assessment of unrestrained walking features, Instrum. Meas. Technol. Conf. (2004) 881-883.
[26] T.F. Novacheck, The biomechanics of running, Gait Posture 7 (1998) 77-95.

27] R.E. Richards, M.S. Andersen, J. Harlaar, J.C. van den Noort, Relationship between knee joint contact forces and external knee joint moments in patients with medial knee osteoarthritis: effects of gait modifications, Osteoarthr. Cartil. 26 (2018) 1203-1214.

[28] P. Legendre, Coefficient of concordance, in: N.J. Salkind (Ed.), Encyclopedia of Research Design, Vol. 1 SAGE Publications, Los Angeles, 2010, pp. 164-169.

[29] J. Cohen, A power primer, Psychol. Bull. 112 (1992) 155-159, https://doi.org/10. 1037/0033-2909.112.1.155.

[30] J. Cohen, Statistical Power Analysis for the Behavioral Sciences, 2nd ed., (1988), https://doi.org/10.4324/9780203771587.

[31] J.M. Bland, D.G. Altman, Agreement between methods of measurement with multiple observations per individual, J. Biopharm. Stat. 17 (2007) 571-582.

[32] A. Mannini, D. Trojaniello, U. Della Croce, A.M. Sabatini, Hidden Markov modelbased strategy for gait segmentation using inertial sensors: application to elderly, hemiparetic patients and Huntington's disease patients, Proc. Annu. Int. Conf. IEEE Eng. Med. Biol. Soc. EMBS, 2015-Novem, 2015, pp. 5179-5182.

[33] B.R. Greene, D. McGrath, R. O'Neill, K.J. O'Donovan, A. Burns, B. Caulfield, An adaptive gyroscope-based algorithm for temporal gait analysis, Med. Biol. Eng. Comput. 48 (2010) 1251-1260.

[34] K. Aminian, B. Najafi, C.B. Ula, P.-F. Leyvraz, P. Robert, Spatio-temporal parameters of gait measured by an ambulatory system using miniature gyroscopes, J. Biomech. 35 (2002) 689-699.

[35] J.M. Jasiewicz, J.H.J. Allum, J.W. Middleton, A. Barriskill, P. Condie, B. Purcell, R.C.T. Li, Gait event detection using linear accelerometers or angular velocity transducers in able-bodied and spinal-cord injured individuals, Gait Posture 24 (2006) 502-509.

[36] D.W. Morgan, P.E. Martin, G.S. Krahenbuhl, F.D. Baldini, Variability in running economy and mechanics among trained male runners, Med. Sci. Sport. Exerc. 23 (1991) 378-383. 
Karlsruher Institut für Technologie

\section{Repository KITopen}

Dies ist ein Postprint/begutachtetes Manuskript.

Empfohlene Zitierung:

Fadillioglu, C.; Stetter, B. J.; Ringhof, S.; Krafft, F. C.; Sell, S.; Stein, T.

Automated gait event detection for a variety of locomotion tasks using a novel gyroscope-

based algorithm.

2020. Gait \& posture, 81.

doi: $\underline{10.5445 / / R / 1000121969}$

Zitierung der Originalveröffentlichung:

Fadillioglu, C.; Stetter, B. J.; Ringhof, S.; Krafft, F. C.; Sell, S.; Stein, T.

Automated gait event detection for a variety of locomotion tasks using a novel gyroscopebased algorithm.

2020. Gait \& posture, 81, 102-108.

doi:10.1016/i.gaitpost.2020.06.019 